
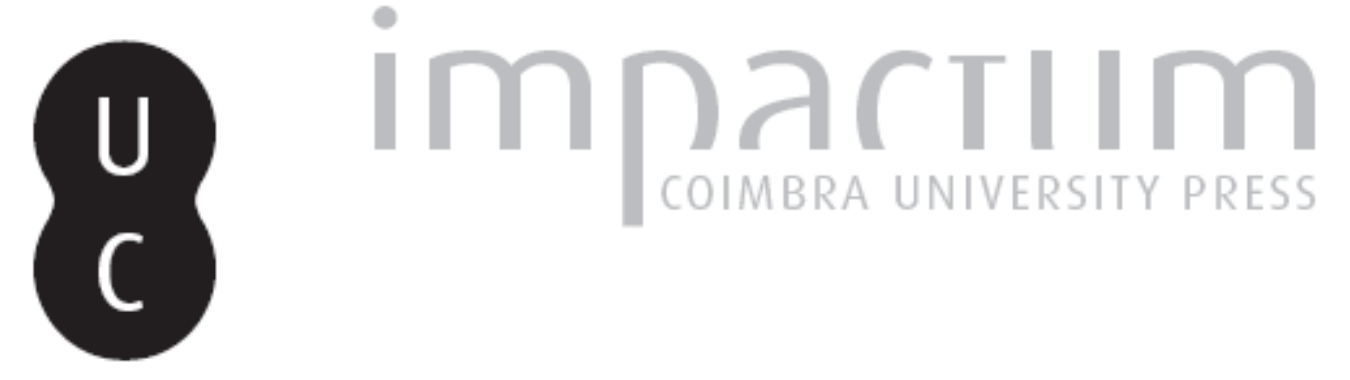

\title{
[Recensão a] CORRADINI, Pietro (dir.) - Della entrata della Compagnia di Giesù e Christianità nella Cina
}

\author{
Autor(es): $\quad$ Rodrigues, Manuel Augusto
}

Publicado por: Centro de História da Sociedade e da Cultura

URL

persistente:

URI:http://hdl.handle.net/10316.2/39541

DOI:

DOI:http://dx.doi.org/10.14195/1645-2259_10-2_15

Accessed : $\quad$ 26-Apr-2023 12:58:33

A navegação consulta e descarregamento dos títulos inseridos nas Bibliotecas Digitais UC Digitalis, UC Pombalina e UC Impactum, pressupõem a aceitação plena e sem reservas dos Termos e Condições de Uso destas Bibliotecas Digitais, disponíveis em https://digitalis.uc.pt/pt-pt/termos.

Conforme exposto nos referidos Termos e Condições de Uso, o descarregamento de títulos de acesso restrito requer uma licença válida de autorização devendo o utilizador aceder ao(s) documento(s) a partir de um endereço de IP da instituição detentora da supramencionada licença.

Ao utilizador é apenas permitido o descarregamento para uso pessoal, pelo que o emprego do(s) título(s) descarregado(s) para outro fim, designadamente comercial, carece de autorização do respetivo autor ou editor da obra.

Na medida em que todas as obras da UC Digitalis se encontram protegidas pelo Código do Direito de Autor e Direitos Conexos e demais legislação aplicável, toda a cópia, parcial ou total, deste documento, nos casos em que é legalmente admitida, deverá conter ou fazer-se acompanhar por este aviso.

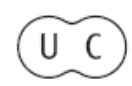




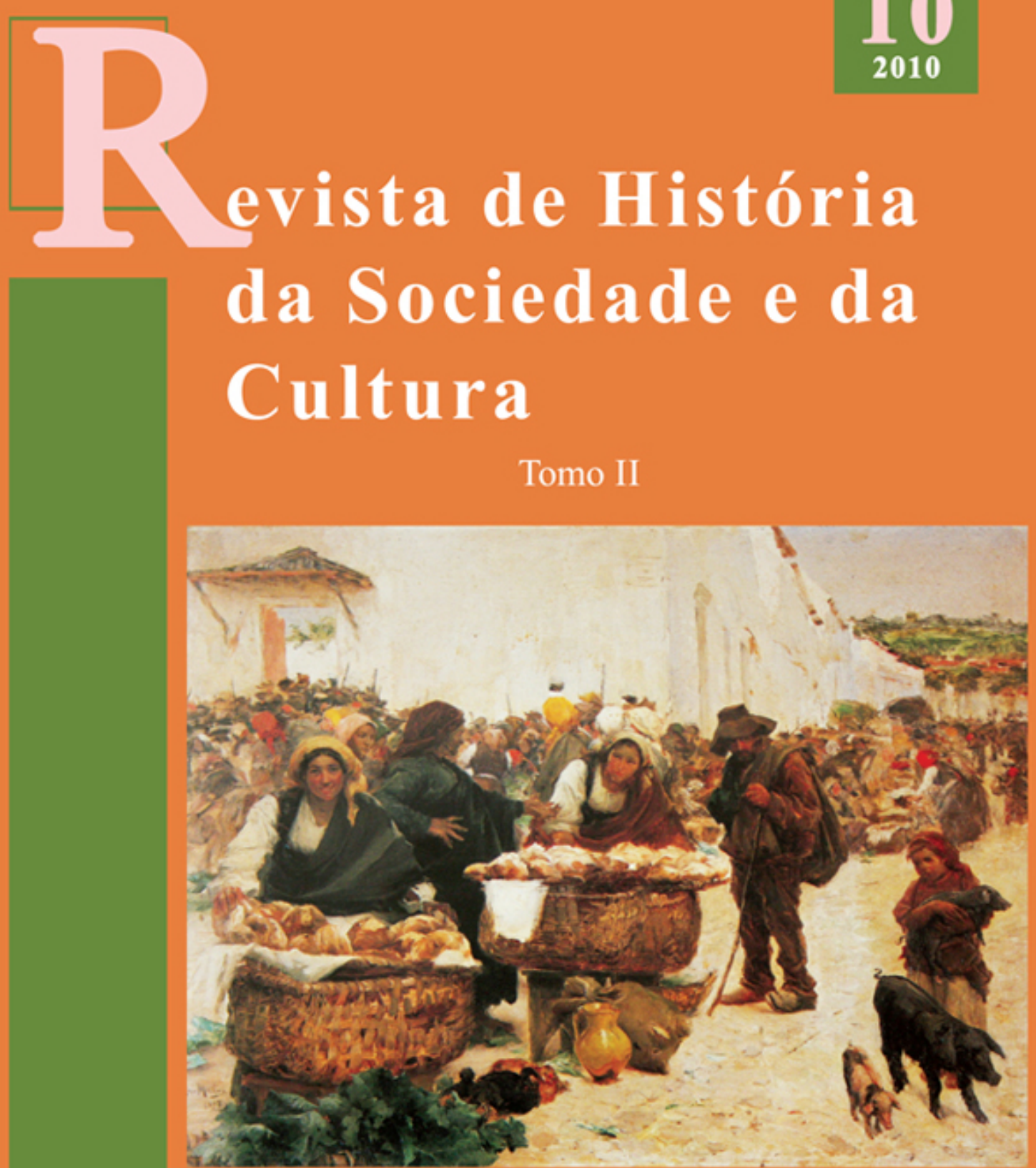

Centro de História da Sociedade e da Cultura Universidade de Coimbra

Coimbra 
santo, conferido às pessoas e lugares, possuía um significado determinante: definia, delimitava e marcava as diversas fronteiras da fé e os limites sociais, jurídicos, culturais e religiosos dos espaços de conquista.

\section{Paola Nestola}

Bolseira de Pós-Doutoramento da FCT, no Centro de História da Sociedade e da Cultura paola.nestola@tin.it

CORRADINI, Pietro (dir.) - Della entrata della Compagnia di Giesù e Christianità nella Cina, com prefácio de Filippo Mignini e edição de Maddalena Del Gatto. Obra realizada pela Província de Macerata-Assessorato Beni e Attività Culturali com o contributo da Regione Marche-Assesorato da Cultura. Macerata: Quodlibet, 2000, 776 p.

No prefácio intitulado "Nel segno di Matteo Ricci”, Filippo Mignini trata do significado da vida do célebre padre jesuíta para a história das relações entre o Oriente e o Ocidente. O P. N. Trigault acrescentou cerca de 19 fólios aos 122 autógrafos do próprio Ricci, segundo a reconstrução de P. D'Elia. Foi preciso esperar três séculos, até 1911, para que o livro fosse publicado pelo P. P. Tacchi Venturi com o título Commentarij della Cina.

Sobre a vida e a obra de M. Ricci (o Li Madou), que viveu durante a dinastia chinesa Ming (1368-1644), escreve P. Corradini um texto em que aborda a importância que teve a Companhia de Jesus e Portugal nos contactos culturais, comerciais e outros com o mundo oriental. Fala do texto e das várias edições e desenvolve alguns temas de especial relevância: o alcance da obra de Ricci e a introdução da civilização europeia na China; Ricci e o conhecimento da China na Europa; Ricci perante a civilização chinesa; a visão ricciana do pensamento chinês; a sua atitude em confronto com as outras religiões; e salienta a inteligência e o tacto do ilustre filho de Macerata na aproximação que criou entre o cristianismo e as religiões da China; assim traduziu o nome de Deus por Tianzhu ("Senhor do Céu", para os convertidos, Shangdi ("Senhor do Alto") e Tian ("Céu") para os não convertidos. As controvérsias foram subindo de tom até que Roma interveio. Queria saber- 
-se o que Ricci pensava exactamente do confucionismo e exigia que ele negasse os cultos populares chineses que ele adaptou à tradição cristã. Viria depois a questão dos ritos que ensombrou a missionação.

Com o Concílio Vaticano II a situação alterou-se: as outras religiões e culturas são hoje vistas de forma positiva e o diálogo tornou-se um instrumento obrigatório. O conceito de "inculturação" que Ricci intuiu e praticou é hoje reconhecido como fundamental. A própria Cúria de Macerata já iniciou o processo da sua beatificação. Na China a sua figura é bastante admirada: "o Sábio do Ocidente" é considerado como um precursor da modernização científica e cultural do país, as suas obras são traduzidas, os estudos sobre a sua pessoa prosseguem e o seu túmulo, que foi alvo dos excessos da Revolução Cultural, foi recuperada e actualmente é um muito visitado.

Os capítulos sobre a bibliografia ricciana incluem: produção literária, edições realizadas, miscelâneas e reportórios bibliográficos, biografia, publicações sobre a actividade missionária, monografias sobre alguns aspectos da sua obra, Ricci e as outras doutrinas e a arte ocidental na China. Vem a seguir uma secção de notas ao texto e várias ilustrações.

A obra contém cinco livros que, por sua vez, são divididos em capítulos, sendo alguns dos textos escritos em português. No livro I trata da razão de escrever esta história e da forma da sua elaboração; do nome, grandeza e localização da China; das coisas que a China produz; das artes mecânicas do país; das artes liberais, ciências e graus concedidos na China; do governo do país; das cortesias e de alguns ritos da China; da fisionomia, culto do corpo, vestuário e outros costumes da China; e fala ainda das várias seitas e de outros assuntos.

Acerca da China escreve: «Este último reino oriental chegou ao conhecimento dos nossos europeus sob vários nomes. $\mathrm{O}$ mais antigo que é do tempo de Ptolomeu é Sina (Sinai no seu Almagesto); no tempo de Tamorlano (Temur Leng ou Lenk (1336-1405), Temur o Zoppo, foi um chefe muçulmano do Turkestão, criador de um vasto império que compreendia a Pérsia, a Mesopotâmia a Índia e a Anatólia; morreu quando se preparava para conquistar a China («como depois se verá; tivemos notícia por Marco Polo com o nome de Cataio (Polo (1254-1324) que viveu na China de 1275 a 1292 chama-lhe Qitan ou Kitai, portanto Catai). Mas o mais célebre destes 
tempos é o de China, divulgado pelos portugueses, que através de longas e perigosas viagens chegaram a Cantão...E é coisa digna de nota que todos esses nomes foram acrescentados da palavra Grande; costumam chamar-lhe "Magna Sina", e Marco Polo designa-a por grande Cataio, e os espanhóis "a Grande China", por onde se vê ser-lhe devida e conatural a sua magnitude e a grandeza do seu nome».

No livro II o autor aborda a entrada dos jesuítas no território, as tentativas de obter autorização de residência, a permanência em Sciaochino, o diálogo sobre a religião cristã, a deslocação do padre Ruggeri a Macau, a chegada de outros jesuítas, a ida de Ruggieri a Roma, o método de evangelização em Zhaoqing, etc.

O livro III elucida-nos, entre outros factos, acerca da residência de Sciaocieo, da decisão de Valignano de iniciar a missão em novos moldes, da visita do padre Sande, da morte do padre A. de Almeida, da ida de Ricci a Nanhium onde converteu vários chinese, da sua deslocação pela primeira vez à corte de Nanquim, da amizade estabelecida com os dois principais parentes do rei e do envio pelo P. Sande e do seu confrade João Soeiro àquela cidade.

No livro IV temos a ida de Ricci a Nanquim, a visita dos padres à corte de Pequim e do regresso a Nanquim, o início da docência de matemática feita por Ricci, os contactos com pessoas de Nanquim, que queriam avistar-se com Ricci, a disputa com um ministro dos ídolos, outra viagem a Pequim, os laços de amizade que criaram, a conversão do doutor Siu Paolo, entre outros temas.

No livro $\mathrm{V}$ fornece-nos notícias da chegada do Japão a Macau do P. Alexandre, do crédito alcançado pelas obras de Ricci, da concessão do grau de doutor em Letras em 1604 em Pequim ao doutor Siu Paolo, dos livros chineses sobre os missionários, da morte do padre A. Valignano, de perseguições várias, da expedição de Bento de Góis e da sua morte, bem como da de Ricci e do seu túmulo.

O nome de Coimbra vem referido duas vezes: a primeira a propósito do P. J. Soeiro que, tendo-se sentido mal de saúde, foi mandado para Macau em 1606 onde viria a falecer com 41 anos de idade. Como diz o texto (p. 536), era português, natural de Montemor-o-Velho, estudou em Coimbra e foi mandado para a India e Macau. Foi um exemplo de jesuíta e de missionário. A segunda vez é quando se fala da morte de Ricci fornecendo 
o autor pormenores sobre a sua vida. Diz que ele se dirigiu a Portugal, tendo passado a maior parte do tempo em Coimbra, porque só nos meses de Março e Abril é que havia passagem para o Oriente e Ricci chegou em Junho.

Aparecem ao longo da obra referências a jesuítas célebres: Acquaviva, C. Clavio, N. Longobardo, P. Mendes, N. Trigault, M. Ruggieri e A. Valignano (1559-1606), nomeado visitador de todas as Índias Orientais. Em 1578, chegou a Macau e no ano seguinte, antes de partir para o Japão, estabeleceu as bases da criação da missão na China; com Michele Ruggieri iniciou uma política missionária inovadora, afirmando ser oportuno interromper a tradição segundo a qual os convertidos tinham de abandonar a sua língua e os seus costumes e adoptar modelos da vida europeia. Compreendeu em particular a necessidade de proceder a uma "sinização" dos missionários no que toca à China. Eles deviam estudar o idioma e a cultura chineses e aproximar-se aos usos e costumes da população. Para pôr em prática este projecto chamou Ricci que lhe deu todo o seu apoio. Mas a ordem não viu com bons olhos essa abertura e Valignano teve de deixar o cargo de visitador sendo nomeado provincial da Índia e dividindo a sua actividade pelo Japão, Macau e Goa. Apoiou totalmente a metodologia seguida por Ricci relativamente à forma como exercia o apostolado e à adopção dos hábitos literários, e aconselhando-o a chegar a Pequim, nomeando-o superior da missão chinesa em 1598 e aprovando o texto latino do Catecismo de Ricci.

Encontramos também alusões a judeus: Ai Tian, nascido por volta de 1545, que Ricci conheceu em Pequim a 1 de Julho de 1605, forneceu-lhe as primeiras notícias de comunidades cristãs na China. Ai Tian e os mercadores persas que chegavam a Pequim revelaram a presença de pessoas que mantinham no seu culto a veneração da Cruz.

E figuram muitos nomes de portugueses, chineses e outros quase: os jesuitas A. de Almeida, J. Barradas, F. Cabral, M. Carneiro (1515-1583) que foi nomeado bispo de Niceia em 1555 na perspectiva de obter o patriarcado da Abissínia. Chegado a Goa, foi nomeado bispo da cidade. Em 1566 foi enviado para a China e o Japão. Governou o bispado de Macau até 1581, ano em que chegou o primeiro prelado, Leonardo de Sá); outros padres mencionados são V. Carvalho, G. Coelho, M. Dias, G. Ferreira, Bento Góis (1562-1607) (a quem o visitador da Índia ordenou que fosse ao mítico Cataio, atravessando a Ásia Central; devia verificar se o Cataio de Marco Polo era 
a China e Cambalu Pequim e também visitar as comunidades cristãs do centro da Ásia), L. Jorge, F. Martines, P. Mendes, N. Pimenta, P. Ribeiro, J. da Rocha (trabalhou intensamente em várias missões, baptizou em 1603 Xu Guangji em Nanquim e escreveu alguns textos sobre a religião cristã), J. Rodrigues, Duarte Sande (chegou a Goa em 1578 juntamente com Ricci e Ruggieri e foi o tradutor de uma das primeiras obras em latim impressas em Macau, o De missione legatorum jiaponensium ad Romanam Curiam de 1589), F. da Silva, M. da Silva, M. Soares, J. Soeiro, M. Teixeira, R. Vicente, G. Viegas e R. Viegas.

Como chineses convertidos temos, entre outros, J. Fernandes (Zhong Ming), S. Fernandes (Zhong Mingren), F. Martines (Huang Mingsha), P. Mendes (Qiu Liangou) e M. Pereira (You Wenhui).

Esta excelente obra, pelo seu conteúdo e pelas notas que inclui, constitui uma das melhores formas de homenagear Matteo Ricci, o grande cientista e missionário da China, no centenário da sua morte.

\section{Manuel Augusto Rodrigues}

Universidade de Coimbra e Centro de História da Sociedade e da Cultura da UC. mrodrigues@ci.uc.pt

RICCI, Matteo - Lettere (1580-1609), edição dirigida por Pietro Corradini, elaboração de Francesco D'Arelli e prefácio de Filippo Mignini com um estudo de Sérgio Bozzola. Opera realizzata dalla Província di Macerata - Assessorato Beni e Attività Culturali con il contributo della Regione Marche - Assessorato alla Cultura. Macerata: Quodlibet, 2001, 620 p.

As 54 cartas contidas no livro foram todas escritas do Oriente (Cochim, Goa, Macau, Zhaoqing, Cantão, Shaozhou, Nauchang, Nanquim e Pequim) entre 1580 e 1609 . O texto das cartas que vem apresentado, salvo poucas variantes expressamente assinaladas, é extraído do vol. II das Opere storiche del P. Matteo Ricci S. I., que foram publicadas pelo "Comitato per le onoranze nazionali” com proémio, notas e tabelas do P. Pietro Tacchi Venturi S. I., 